\title{
O projeto de "Africanidade global" para uma escrita da história da diáspora africana
}

Ana Cristina Juvenal da Cruz*

* (Universidade Federal de São Carlos
- UFSCar, São Carlos-SP, Brasil)
Resumo: Este artigo apresenta algumas notas para uma discussão sobre a interpretação e narrativa histórica em torno da escrita da história da África contemporânea. A proposta se vincula a um debate no interior da proposição de uma "Africanidade global" apresentada por historiadores e historiadoras dedicadas ao estudo desse campo. Ainda como um conceito emergente, o que se configura como "Africanidade global" é uma espécie de genealogia da experiência das populações africanas e seus descendentes no espaço da diáspora. A proposta insere e articula as diferentes motivações, contextos e consequências das diásporas africanas na longa duração e em sua diversidade. Pretende-se contribuir com esse debate junto à introdução de aspectos teóricos e metodológicos que balizam o cenário contemporâneo da discussão historiográfica contemporânea da leitura de novos aportes à historiografia africana.

Palavras-chave: História da África. Diáspora africana. Africanidade global. 
INTRODUÇÃO

As mudanças, rupturas e continuidades interpretativas dos paradigmas epistemológicos da modernidade geraram nos últimos tempos consequências em torno das narrativas sobre o modelo de pensamento que estrutura o modo de escrita da História que forja o sujeito moderno ocidental. Tal modelo em disputa tem trazido mudanças não apenas conceituais sobre a aplicabilidade das categorias de análise, mas possibilitado o reposicionamento de outras posturas políticas em torno do amplo e disputado campo daquilo alocado no campo das diferenças. Isso não carrega necessariamente uma novidade. A disputa sobre as diferenças e sua conceituação tem longa data. 0 que se percebe como inovador é o lugar que ocupa quem denomina e fala sobre as diferenças.

Especialmente no que tange à questão racial, tal movimento tem sido realizado junto à percepção crítica da não realização do projeto iluminista moderno. Paul Gilroy (2001) sugeriu que a criatividade necessária para tal análise estaria na "história da diáspora africana” (GILROY, 2001, p. 109). Há, nessas proposições, uma leitura dos limites de compreensão de um universalismo de base colonial cujo legado foi instaurado no interior de uma concepção da existência de uma gramática comum dos conflitos sociais fornecidos por uma "racionalidade comunicativa", nos termos de Jürgen Habermas (2004).

Há no interior desse debate um reposicionamento da questão das diferenças, como as de base racial no campo do reconhecimento, tal qual a experiência constituída nos anos de 1990, com a ascensão das multiplicidades no interior do campo político. No momento em que esses pressupostos são questionados, surgem novas perspectivas direcionadas à intelectualidade e a perspectivas teóricas, especialmente pelos movimentos sociais e migratórios de todo tipo que reposicionam as instituições modernas, as identidades e os discursos legitimadores de alguns paradigmas.

O debate contemporâneo está assentado nas discussões sobre a convivialidade e a dimensão transnacional. Tal debate tem apontado para o desafio do estabelecimento de políticas públicas voltadas a todos os segmentos populacionais. As relações étnico-raciais, de gênero, de sexualidade, de classe social, de acessibilidade e das pessoas com necessidades educacionais especiais são temas internacionalizados e seus desdobramentos, como as diversas desigualdades que emergem de concepções equivocadas em torno 
dessas questões, exigem ações cientificamente embasadas e politicamente orientadas. O objetivo aqui é o enfoque em como as ideias de raça são perpetuadas sem uma crítica profunda aos modos de sua constituição como um produto moderno.

Uma pletora de intelectuais tem apresentado uma ligação direta entre a universalidade e o iluminismo modernos que sustentaram concepções raciais que foram utilizadas como justificativa do escravismo africano negro e da colonização. Suas ações têm sido no sentido de "reconstruir a história primordial da modernidade a partir do ponto de vista dos escravos" (GILROY, 2001, p. 126). O que leva à discussão aqui é a impossibilidade de alguns paradigmas que se colocam a partir das experiências locais. 0 que se aponta é que o terror racial ${ }^{1}$ é constitutivo da racionalidade ocidental, mas tal concepção somente pode ser alcançada na compreensão do que era a "rebelião, suicídio, fuga e luto silencioso" no interior da escravidão africana moderna e da plantation (GILROY, 2001, p. 129), onde não havia nenhuma possibilidade de uma gramática que pautasse a razão comunicativa. Há aqui a possibilidade de dois pontos de inflexão. 0 primeiro é que, como utilizado por Gilroy (2001), o “terror racial” que marca a racionalidade moderna é parte constitutiva da modernidade ocidental e, consequentemente, de seu legado. Se, por um lado, é possível atribuir sua temporalidade à escravidão, por outro, seu modo de funcionamento estrutura racialmente as sociedades e o modelo de pensamento moderno. 0 segundo ponto de inflexão que surge dessa leitura é que mesmo sob o "terror" as experiências de resistência das fugas, das rebeliões, entre outras práticas, atribuíram ao sujeito sob a lógica da escravização o caráter de agentes de sua história.

0 advento dessa mudança de interpretação e da necessidade de outra gramática em outro pensamento crítico se assenta no momento de deslocamento da Europa como irradiador central, na qual o restante do mundo gravitaria. Tal cenário ressoa para Achille Mbembe (2014) de três momentos: 0 primeiro foi o tráfico atlântico, que transformou mulheres e homens africanos em "homem-objeto, homens-mercadoria e homens-moeda", o segundo o acesso pelos negros à escrita e a produção de uma linguagem para si e, por fim, o terceiro momento é a ordenação contemporânea dos mercados globalizados na privatização do mundo sob o neoliberalismo (MBEMBE, 2014, p. 12-13). Desses momentos derivam, entre outras coisas, a ascensão

O "terror racial" é um termo utilizado para caracterizar as práticas de violência que estruturaram a escravidão africana durante a modernidade ocidental. Paul Gilroy assim define: "o terror racial não é meramente compatível com a racionalidade ocidental, mas, voluntariamente cúmplice dela” (GILROY, 2001, p. 127). 
de uma espécie de espraiamento da experiência às quais os escravizados negros foram expostos para todas as "humanidades subalternas" (MBEMBE, 2014, p. 16), o que Mbembe denomina “o devir-negro do mundo" (p. 18). As questões colocadas somam-se a um pensamento crítico contemporâneo sobre os desafios do nosso tempo. Há que se identificar onde e como estão sendo gestadas as mutações no campo do pensamento sobre a questão racial na contemporaneidade. Algumas dessas mutações retém aspectos de um amplo lastro de elementos do campo das ideias. As analíticas colocadas no interior da experiência da diáspora africana e da narrativa da sua história apresentam questões criativas e necessárias a partir das ideias colocadas em curso no que se serviu da história para a formulação discursiva e prática da “razão negra” (MBEMBE, 2014, p. 25).

O caso do Haiti, que elevou a população haitiana como enunciadora dos ideais revolucionários modernos, de liberdade, igualdade, emancipação, entre outros, apenas na contemporaneidade ascende suplantando as solapadas análises filosóficas e históricas. Susan Buck-Morss (2017) aponta como em diversos pensadores iluministas havia uma exaltação à liberdade e, ao mesmo tempo, uma condescendência em relação à escravização da população negra africana. Há que se inserir na análise da questão racial contemporânea o uso da condescendência histórica com a qual esse pensamento se manteve sob a égide de certo anacronismo. Há, portanto, a possibilidade de uma análise qualificada que considere a escrita performática da história. Isso permitirá considerar o legado da população de descendentes de africanos escravizados dos modos como se tornaram agentes da sua história.

DEBATES EM CURSO EM TORNO DAS BASES EPISTEMOLÓGICAS DA HISTÓRIA AFRICANA

A publicação da Coleção História Geral da África (HGA) pela Organização das Nações Unidas para a Educação, a Ciência e a Cultura (Unesco) na década de 1960 refletiu uma mudança de orientação no âmbito da Organização das Nações Unidas (ONU) sobre o continente africano. Kouassi (2010) analisa as ações da ONU como "modestas" e "paternalistas" em relação ao que o continente africano necessitava naquele momento.

As independências dos países africanos forçaram mudanças significativas nesse modelo de relações internacionais. Os anos 1960 marcaram o debate sobre o colonialismo junto a uma internacionalização dos denominados estudos africanos, da produção de uma história da África escrita por 
africanos, da proposição pan-africana, que, entre outras questões, pautouse por críticas políticas às ciências filosóficas e antropológicas em torno de uma antropologia do indivíduo (que alocava os africanos no campo da natureza e não da razão), da potência trazida pelo movimento literário e intelectual da négritude e às narrativas históricas que atuaram e sustentaram o colonialismo. 0 movimento da negritude derivada do pensamento de Aimé Cesaire associou uma produção literária militante aos embates políticos pela libertação junto ao pan-africanismo.

Aquele momento marcou uma temporalidade fundamental no entendimento desse contexto, pois 16 países africanos tornaram-se independentes ao mesmo tempo que o pan-africanismo se consolidava como "um conjunto de relações unindo os africanos além das suas fronteiras territoriais” (MAZRUI, 2010, p. 1106). O pan-africanismo era gestado no interior da proposição da construção de uma leitura mais ampla, nas ideias gestadas pelos Congressos pan-africanos desde 1900, que semearam interpretações sobre as diferentes experiências dos povos africanos e apresentando indicações que atualmente embasam as perspectivas contemporâneas da leitura historiográfica.

Essa proposta já se delineava quando da criação da Societé Africaine de Culture (1949), que, por meio da revista Presence Africaine, colocava como pauta política a elaboração de uma "história da África descolonizada" este intento é a origem da posterior elaboração do projeto História Geral da África (KI-ZERBO, 2010, p. 20). O primeiro número da Presence Africaine define o objetivo da revista, escrito por seu editor, André Gide. Para além de interpretar o desejo de não submissão a qualquer ideologia ou política de cunho eurocêntrico, se abria à colaboração para uma "originalidade africana" inserida no naquele mundo moderno (GIDE, 1947). O documento da 16aㅡ Conferência Geral da UNESCO de 1960, que estabeleceu a convocação para a Conferência dos Estados Africanos em 1961, indica: “com o objetivo de fazer o inventário de suas necessidades em matéria de educação e estabelecer, para os povos vindouros um programa de ação em resposta a essas necessidades" (KOUASSI, 2010, p. 1085).

Na revista $O$ Correio da Unesco, de 1979, foi publicada uma edição especial sobre os caminhos metodológicos da historiografia da África que orientaram a elaboração da HGA com alguns dos pesquisadores que tiveram artigos publicados nos volumes (CRUZ, 2014). Entre os textos dedicados ao debate metodológico, destacam-se os de Joseph Ki-Zerbo (1979), Amadou Hampâté Bâ (1979) e Amadou-Mahtar M’Bow (1979). Os autores versaram sobre vários 
aspectos da descrição dos objetivos com a HGA de abordar a história das civilizações, das sociedades e das instituições, e de se constituir como uma obra de síntese, considerando as diversas correntes de pesquisa até aquele momento elaboradas sobre a África. Ki-Zerbo alertava sobre o cuidado com a metodologia na elaboração de uma história sobre o continente africano. Além disso, descreveu exemplos que poderiam auxiliar a escrita de uma história africana destacando que o colonialismo havia operado uma ruptura na história da África (KI-ZERBO, 2006). Segundo Ki-Zerbo, tal movimento adentrou a estrutura social de modo violento por romper com os elementos de ligação com seu grupo de pertença, ao impedir que pudesse expressarse em sua língua, proferir seus cultos próprios, se movimentar no espaço. No entanto, mesmo sob a colonização, muitas sociedades africanas lograram manter alguns de seus elementos culturais e potencializar estratégias de resistência.

A reivindicação em torno da descolonização das nações africanas não se limitava às liberdades políticas, mas também à produção epistêmica. Ali Mazrui (2010) afirma dois desafios ao continente africano nos anos 2000. Um trata da questão dos sexos. Segundo ele, houve mudanças nos papéis de homens e mulheres na vida pública do continente. Esse tema demasiado amplo não poderá ser aqui explorado com profundidade, mas cabe ressaltar o desafio do caráter das relações entre "relações estabelecidas entre os indivíduos áfricos, de parte a outra da fronteira sexual” (MAZRUI, 2010, p. 1106-1107). Tal questão trata da posição de homens e mulheres no campo social, da divisão de poder, entre outros desafios. O segundo desafio, que se aproxima do debate aqui apresentado, trata da "revolução científica" que, segundo Mazrui (2010), é a de uma educação direcionada ao desenvolvimento. Se, de um lado, a formação ocidentalizada ofertada às populações africanas levou à base de libertação via independência dos países, de outro, a colonização interrompeu a marcha do desenvolvimento científico africano, deixando como legado a ausência de uma formação para as "técnicas produtivas" que limitou o desenvolvimento do continente (MAZRUI, 2010, p. 1115).

A percepção da estrutura do colonialismo agregando o alastramento de práticas em diversos sentidos levou a um entendimento de seu caráter epistêmico. Isso gerou um primeiro movimento de uma historiografia africana desenvolvida nesse período identificado como era da "euforia" (MKANDAWIRE, 2005). Os investimentos em pesquisa em instituições africanas na década de 1960 se integraram a um movimento de reconstrução do passado e projeção de uma escrita da história. 
O impacto técnico-científico esteve desde logo na origem da HGA de reposicionamento epistemológico e metodológico. Em seus oito volumes, a coleção aborda questões desde a história antiga e pós-colonial do continente africano, atravessando a história das civilizações, das sociedades e das instituições, constituindo-se como uma obra de síntese, considerando as diversas correntes de pesquisa sobre a África (BARBOSA, 2018). Publicada inicialmente em línguas definidas pela ONU, atualmente a coleção está traduzida em 13 idiomas, entre eles swahili, peul e hausa.

Tomar a Coleção História Geral da África como fonte primária permite desde logo romper com um erro comumente presente nas narrativas históricas: 0 de iniciar uma narrativa da história da África e de seus descendentes pelo colonialismo e a escravidão. Esse erro ecoa na insistência em restringir essa história aos ciclos econômicos das colônias europeias nas Américas e na construção do continente africano como objeto epistêmico (MBEMBE, 1988). Quando não isso, a história da África é subsidiária e refratária da história euroocidental (FURTADO, 2016). Isso levou ao curso de um limite gnosiológico e ontológico que destinou uma representação estereotipada do continente africano e da diáspora negra que ainda se reproduz no campo social.

Joseph Ki-Zerbo argumenta que há sempre uma opção naquilo que adquire lugar na História (KI-ZERBO, 2006). Isso permite olhar o passado sob uma perspectiva que permita meios de ofertar perspectivas sobre o presente. Michel-Rolph Trouillot ([1995] 2016) nos convida a pensar como o passado compõe um discurso sobre o presente. Em outras palavras, há, segundo ele, em toda a afirmação histórica do presente uma relação de atualização do passado. Há nos sujeitos históricos algo de inconsciente em suas ações. Trouillot está na esteira do avanço em torno daquilo que se constituiu a partir do positivismo e do construtivismo na História. Aponta ainda uma crítica à perspectiva positivista da história como se houvesse uma "verdade" a ser descoberta e repassada, e à perspectiva construtivista da narrativa histórica como ficção. Essa própria distinção, segundo Trouillot, é inócua, uma vez que pressupõe a possibilidade de uma desconexão do passado com o presente ao desprezar o próprio processo de construção do discurso, como se a narrativa pudesse apartar-se da vida (TROUILLOT, 2016).

Ainda para Trouillot, o investimento deve ser nas implicações do poder nos silenciamentos e naquilo que é dado a falar. Analisa este fenômeno em cada um dos níveis e aponta como a operação de "silenciar o passado" é feita segundo duas fórmulas distintas e concomitantes: a primeira consiste em promover 
uma constante de generalizações de forma a constituir certo apagamento sobre determinados eventos e pessoas e possíveis consequências; a segunda, que decorre da primeira, incide no movimento de esvaziar eventos singulares de determinados conteúdos, frequentemente por meio de um detalhamento feito de modo a banalizar toda uma rede de acontecimentos. Desse modo, a terminologia utilizada na descrição de um acontecimento demarca as relações de poder que fundam os silêncios e as falas em torno desse acontecimento, de modo que "a autenticidade histórica reside não na fidelidade a um pretenso passado, mas na honestidade em face do presente, uma vez que ele re(a) presenta o passado" (TROUILLOT, 2016).

Esses elementos nos permitem estabelecer os modos a partir dos quais 0 repertório epistemológico e de conhecimentos que derivam das matrizes étnico-raciais e culturais e dos saberes africanos e afrodescendentes é produzido no "espaço da diáspora”, como sugere Avtar Brah (2011). Para Brah, há uma potência no uso da noção de diáspora, pois permite uma relação disruptiva com o tempo. O conceito de espaço da diáspora, segundo Brah, permite a subversão analítica do modelo do Estado-nação caracterizado pela unicidade de um povo, uma língua, um território. Para Brah há uma outra possibilidade epistêmica ao fazer emergir como centralidade não o que é similar essencialmente, mas o plural e a diferença. Ao fraturar o tempo e o espaço e a articulação entre os acontecimentos históricos, o conceito de espaço da diáspora permite conectar genealogias de dispersão no espaço à histórias dos povos que permanecem em espaços localizados (BRAH, 2011, p. 212). Na apreensão diaspórica, o tempo histórico é visualizado não apenas nas continuidades visíveis, mas nos laços de sentido estabelecidos entre esses acontecimentos.

A diáspora pode, portanto, ser utilizada junto a um quadro interpretativo de análise cuja articulação permite traçar e identificar a relação de bens, objetos, pessoas, saberes e culturas. Como categoria analítica, torna plausível conectar espaços, tempos e acontecimentos longínquos cronologicamente, mas que "conversam", na medida em que os ecos das ações perpetradas pelas pessoas encontram ressonância. No espaço da diáspora é onde essas diversas articulações operam entoadas como "dinâmicas de poder de interseccionalidade" (BRAH, 2011, p. 246).

Os estudos da transnacionalidade permitem pensar uma organização social transfronteiriça (BLANCO, 2015). As questões contemporâneas das imigrações, a convivência nos territórios na contemporaneidade, das pessoas 
em condição de refugiadas, se assenta sobre a equação entre o local e o global. Sob tal perspectiva, o questionamento em torno da manutenção do discurso da nação torna-se um ponto de investigação sobre "formações sociais racialmente estruturadas" (HALL, 2009, p. 313). A “questão multicultural” (HALL, 2009), ao colocar no centro do debate político a constituição das nações, as derivações da diferença, das identificações, das pluralizações culturais, modifica os termos centrais a partir dos quais o Estado é politizado: a universalidade, a cidadania, a igualdade, todos os referenciais centrais do Estado-nação.

Achile Mbembe (2014) avalia que a “política do futuro" está assente em questionamentos acerca das relações entre a convivência e a diferença diante de uma "sociedade mundial globalizada" (MBEMBE, 2014, p. 302). Para Mbembe, a noção de afropolitanismo carrega uma centralidade cujo sentido ocorre em considerar uma "sensibilidade cultural, histórica e estética" (MBEMBE, 2015, p. 229). O conceito integra concepções legadas ao panafricanismo e à negritude, e está relacionado com "as ferramentas intelectuais pelas quais as sociedades apreendem seu destino" (MBEMBE, 2015, p. 68). Trata de uma proposta epistemológica pautada em uma:

estilística, uma estética e uma certa poética do mundo. É uma maneira de ser no mundo que recusa, por princípio, toda forma de identidade vitimizadora, o que não significa que ela não tenha consciência das injustiças e da violência que a lei do mundo infringiu a esse continente e a seus habitantes. É igualmente uma tomada de posição política e cultural em relação à nação, à raça e à questão da diferença em geral (MBEMBE, 2015, p. 70-71).

A experiência da diáspora africana é o conceito central a partir do qual se desenha a constituição de outra reconfiguração histórica. Nesse movimento, o conceito se amplia, não se restringindo à experiência da escravidão, mas colocando questões sobre a narrativa e as leituras acerca do processo de dispersão dos povos africanos e seus descendentes. 0 argumento gira em torno de que as metodologias e fontes utilizadas no ensino de história da experiência da diáspora africana são insuficientes para a nova reconfiguração dessas questões. Para Mbembe (2015), as experiências “afropolitanas" da atual Johanesburgo fazem eco ao que foi o Harlem e Nova Orleans, com uma geografia e uma temporalidade imersas desde logo em outra arte, filosofia e estética. É necessário, assim, cartografar as linhas da "circulação dos mundos" (MBEMBE, 2015, p. 68). 
A Década Internacional de Afrodescendentes, em curso desde 2015 e que perdurará até 2024, apresenta como tema "reconhecimento, justiça e desenvolvimento". Idealizada pela ONU, a década está diretamente associada aos esforços empreendidos para recompor e difundir a história e o protagonismo da população afrodescendente. Uma das ações propostas para a década é a edificação de "um memorial permanente na sede da ONU em homenagem à memória das vítimas da escravidão e do tráfico transatlântico de escravos" (ONU, 2015).

A indicação de uma série de atividades está pautada nos seguintes pontos: "reconhecimento, justiça, desenvolvimento e discriminação múltipla e agravada" (ONU, 2015). Tais temas são fundamentais para a construção de restituições, reparações para uma constituição de humanidade. Nas atividades no âmbito do reconhecimento, a ONU insta os países a desenvolverem ações de "educação para a igualdade e ampliação da conscientização"; um dos tópicos refere-se a "promover um maior conhecimento, reconhecimento e respeito pela cultura, história e patrimônio dos povos afrodescendentes, inclusive através de pesquisa e educação, e promover a inclusão completa e precisa da história e da contribuição dos povos afrodescendentes nos currículos escolares" (ONU, 2015).

Tais questões estão na pauta do debate internacional em torno de princípios basilares de reciprocidade e de cooperação entre os povos, tais como o reconhecimento de direitos, da não discriminação, garantia da igualdade de direitos, de respeito mútuo entre os Estados, da igualdade de oportunidades e ética da cidadania global, da diversidade étnico-racial e cultural, entre outros princípios. A orientação etnocêntrica presente na historiografia que orientou por um longo período os currículos contemporâneos, entendidos como lócus de produção de um conhecimento acadêmico específico, sublimou em seu espaço as experiências e saberes africanos e afrodescendentes. Isso pôde ser visualizado nos últimos anos por meio das diversas políticas de reconhecimento multicultural em diferentes contextos nacionais, especialmente na área da educação, que possibilitaram a ampliação dos conhecimentos acerca das influências das matrizes africanas e da diáspora negra nas ciências naturais, humanas e exatas.

No Brasil, as legislações sobre ensino específico da história de grupos étnicoraciais distintos derivadas de uma extensa luta política dos movimentos sociais negros e indígenas, ao serem promulgadas, representam um avanço no que se refere à narrativa construída pela nação brasileira. As Diretrizes 
Curriculares Nacionais para a Educação das Relações Étnico-Raciais e para 0 Ensino de História Afro-Brasileira e Africana (2004) indicam conteúdos que devem estar integrados em diferentes áreas de conhecimento. Em termos de debate político, fizeram emergir os capítulos ainda difíceis da história brasileira. Mostram que é imperativo no Brasil estabelecer um movimento para se reconciliar com a sua história - a admissão da nossa constituição histórica que deve considerar os reflexos da colonização e da escravidão negra no passado e no presente. Mas, para além, desafiam nossa percepção ao nos forçarem a incorporar os saberes, conhecimentos desenvolvidos pela experiência dos povos negros e indígenas.

Tal questão pode ser visualizada em um contexto global. No caso da França, legislações como são a Lei Gassot (n. 90-615, 1990) impedem narrativas sobre a negação do holocausto, contra a negação do genocídio armênio. Há ainda a Lei Taubira (2001-434) que não apenas institui o escravismo e a escravidão como crimes contra a humanidade, seguindo a recomendação da ONU. Pap Ndiaye (2005) afirma que há um debate sobre o modo como os negros ocupam um espaço ambivalente e minoritário no espaço social francês. Minoridade é um qualificativo para descrever, por um lado, o processo de identificação dos negros franceses enquanto grupo, e, por outro, de determinada constituição de uma política racial negra na França que deriva de tal identificação (NDIAYE, 2005).

Na Colômbia, a Lei 70, de 1993 e o Decreto 2.249, de 1995, conhecidos como as "leis das comunidades negras", implicam não apenas medidas de proteção dessas comunidades, mas de preservação e valorização de suas construções identitárias no campo da educação. Legislações como essas colocam novas questões ao ensino de história na medida em que os temas do escravismo, da imigração e da colonização modificam o campo (FALAIZE, 2009, 2014).

Em termos de alinhamentos acadêmicos, em torno de novas bases epistemológicas, os estudos subalternos, culturais e pós-coloniais agregam um conjunto de pressupostos que levam a questões específicas no que tange à construção da narrativa histórica. Os estudos subalternos, estudos póscoloniais e estudos culturais têm um ponto de encontro comum ao se voltarem para as formas de construção das narrativas utilizadas para constituição da nação (FISTETTI, 2009).

Os estudos subalternos, derivados das instituições indianas, constituemse em uma corrente historiográfica cuja crítica epistemológica dirige-se aos métodos históricos e científicos que produzem a condição de subalternidade. 
Um dos desdobramentos que derivam desta crítica epistemológica refere-se à escolha da metodologia a ser adotada na medida em que aborda de forma crítica a utilização e análise das fontes históricas. Os estudos subalternos propõem ampliar o horizonte do que foi construído sob a lógica de análise metodológica marxista como modelo conceitual. Propunham uma "história vista de baixo" a partir do contexto indiano que implicava o rompimento com o "paradigma nacionalista" e uma crítica ao marxismo ortodoxo que pautava de modo predominante a historiografia indiana (POUCHEPADASS, 2000). Com a proposição de outra historiografia a partir de uma reescrita da história e das narrativas dos povos, especialmente os que estiveram sob o domínio colonial, havia o objetivo de "restabelecer o povo como sujeito de sua própria história”, além de operar uma mudança do eixo cultural a partir do qual se centraria a análise.

Para além do que pode sugerir certa centralidade simplificada da cultura, os estudos culturais, derivados das instituições acadêmicas britânicas, dirigemse aos modos pelos quais a cultura atua sobre o social como um campo de força e de disputa, "fazendo proliferar ambientes secundários, mediando tudo" (HALL, 1997, p. 5). Para Stuart Hall, a complexidade deriva da ênfase colocada na textualidade, na representação, no contexto e no modo como esses elementos se configuram como uma formação discursiva culturalmente elaborada e que atribui sentido às relações sociais (HALL, 1996).

Os estudos pós-coloniais, derivados de intelectuais localizados em instituições americanas e europeias, problematizam o colonialismo como experiência histórica e se constituem como um conjunto “híbrido" de estudos. Questionam o investimento no "momento fundador", situando-se em pesquisas segundo as quais o colonialismo, além de se fundar em um projeto que extrapola a estrutura militar-econômica direcionada aos espaços colonizados, é pautado por uma infraestrutura discursiva e um intenso aparelho de poder que atuou com o saber epistêmico e a violência física (MBEMBE, 2016). Para essa perspectiva, mesmo em um contexto desfavorável, o colonizado produz certo modo de experienciar a condição colonial, aquilo que Homi Bhabha (1998) denomina "ambivalência" - o processo pelo qual de modo híbrido as pessoas se utilizam de estratégias para absorver e mesclar as experiências culturais que vivem.

Stuart Hall (2009), ao analisar os usos do termo pós-colonial, alerta para os diversos sentidos atribuídos ao conceito e aponta a necessidade de compreender em quais momentos este é utilizado como uma temporalidade, 
isto é, um momento após o colonialismo ou como elemento de uma dimensão discursiva. No entanto, o pós-colonial como teoria apresenta algumas interrelações indissociáveis: as sociedades formadas a partir do colonialismo, a dimensão racializada constituinte de suas formações e as diferentes formas de descolonização.

Hall (2009) sugere que o pós-colonial, enquanto categoria analítica, seja empregado como termo que assinala os diversos processos de descolonização como parte de um processo transnacional e transcultural com o objetivo de "descrever ou caracterizar a mudança nas relações globais" (p. 101) e assim define: "o termo se refere ao processo geral de descolonização que, tal como a própria colonização, marcou com igual intensidade as sociedades colonizadoras e colonizadas" (HALL, 2009, p. 101), permitindo assim reler a 'colonização' como um processo “transnacional e transcultural - e produz uma reescrita descentrada, diaspórica ou 'global' das grandes narrativas imperiais do passado, centradas na nação" (HALL, 2009, p. 102). 0 termo alia-se, ainda, a outras perspectivas que rompem com as análises binárias ao pluralizar o foco nas histórias locais. Nessa perspectiva, a configuração das relações dadas com o pós-colonial indica os elementos coloniais e póscoloniais incidindo, mesmo que de forma diferenciada, nas sociedades com experiência colonizadora ou colonizada (HALL, 2009).

O pós-colonial, como categoria analítica permite um tratamento de modo intercambiante acerca da temporalidade da modernidade. A processualidade do contexto colonial nos auxilia a considerar o advento de uma modernidade aos locais colonizados na "periferia" e na continuidade dos "terceiros mundos". Isso é fundamental para uma outra compreensão da dimensão racial que é construída a partir da modernidade, cujo substrato é a criação do "negro". Essa nova "moldura temporal" (BHABHA, 1998) possibilita rearticular o que constitui a diferenciação social.

O pós-colonial como corpo teórico é fundamentalmente múltiplo há uma ênfase dada à experiência cultural utilizando uma noção de cultura "fluída", "incomensurável”, “incompleta” vendo-a desde logo como "híbrida”. As alusões que surgem no pensamento pós-colonial como "crítica”, "perspectiva”, "discursos", ou a utilização conjunta destes termos como "discurso crítico póscolonial" apontam a profusão de termos que marca sua fundação (BHABHA, 1998).

O pós-colonial admite depositar discursos, textos e documentos na perspectiva histórica do seu contexto e na situação investida de seu enunciado. 0 prefixo 
“pós”, embora remeta a uma referência temporal, é utilizado mais como um questionamento acerca da narrativa daquilo que se localiza entre "o que é contado" na história e entre "o que aconteceu" na história (MEZZADRA, 2008). Bhabha identificou que "as críticas pós-colonial e negra propõem formas de subjetividade contestatórias que são legitimadas no ato de rasurar as políticas da oposição binária”, ou seja, de ir além das proposições analíticas constituídas pelos binarismos (BHABHA, 1998, p. 249). Como possibilidade metodológica, reside aqui um dos proveitos dos estudos pós-coloniais, o de romper com uma categorização binária entre sexos, gênero, sexualidade, raça, entre outros termos, que em geral é abundantemente presente nas teorias que pensam o social. A utilização da palavra "pós" em outros léxicos (póscolonialismo, pós-moderno, pós-nacional, entre outros), segundo McClintock (2010), revela mais uma crise acerca da ideia de "progresso histórico linear" (MCCLINTOCK, 2010, p. 102).

Achille Mbembe (2008) afirma que o termo pós-colonial mantém em sua heterogeneidade questões que são essenciais como construção crítica. Primeiro, tem-se o questionamento da maneira pela qual um tipo de racionalidade que convivia com um terror racial é negligenciada como estruturante do colonialismo, no interior de "experiência global de representações, técnicas e instituições" (MBEMBE, 2008, p. 2). Mbembe constrói uma cronologia sobre a constituição dos estudos pós-coloniais que se inicia com as lutas anticoloniais e as contribuições dos pensamentos de Frantz Fanon, Léopold Senghor e Aimé Césaire.

A partir de 1980, passam a se configurar algumas das bases do pensamento pós-colonial, sobretudo com a inflexão proposta por Edward Said ao criticar os saberes da modernidade colocados a serviço do colonialismo. Com uma análise criteriosa do orientalismo, Said produz uma obra considerada referência sobre as representações do Oriente, em um livro definido pelo autor como um estudo sobre “cultura, ideias, história e poder” (SAID, 2007, p. 13). Nos anos 1990, a entrada dos estudos subalternos indianos, com o projeto de reescrita das histórias locais e com os estudos "afro-modernos" que Mbembe indica como pautados na leitura da metáfora do Atlântico, das diásporas e das categorias de análise instrumentalizam o pensamento teórico. Há outro aspecto de destaque aqui que trata das lacunas apresentadas pelo espectro pós-colonial apresentadas pela leitura de Stuart Hall (2009), que tratou da incipiente articulação do avanço do capitalismo global. Isso deve considerar uma leitura avançada de um tipo de marxismo reducionista que impede de articular as formas de impacto da dimensão econômica junto às diferentes 
formas nas quais o gênero, a raça, as sexualidades marcam a experiência social. A contribuição de Mbembe (2014) ao sugerir a modernidade como o momento no qual a raça foi aliada ao signo do capital aqui se abre à possibilidade de outra leitura histórica e de novos desafios ao tempo presente.

\section{As CONTRIBUiçÕes EM tORnO dA “AfricanidAde global”}

Em 2013 foi lançado em Adis Abeba o projeto do IX volume da Coleção História Geral da África cujo tema seria centrado em um reposicionamento do lugar da África no mundo. Em 2019, na apresentação do nono volume durante reunião de Comitê Internacional Científico da Organização das Nações Unidas para a Educação, a Ciência e a Cultura (Unesco) realizada no Brasil, destacou-se que o nono volume contará com temas que versarão sobre a experiência da diáspora africana. 0 volume terá diferentes enfoques pautados na pluralidade de conteúdos e debates sobre a presença e o legado do pensamento intelectual, artístico, estético, filosófico, político entre outras dimensões da diáspora africana no contexto global.

O novo volume terá como tema central a "Diáspora africana" sob diversas perspectivas, como a dispersão em diferentes momentos históricos, da história antiga da África à colonização em variadas partes do mundo, o tráfico de escravizados africanos e as experiências de descolonização. Epistemologicamente, o nono volume da HGA se apoia no conceito de Africanité globale ["Africanidade global"], elaborado como um projeto de ruptura epistemológica ao incorporar as diversas formas de dispersão da africanidade na longa duração e em sua diversidade. O conceito de "Africanidade global" em processo de disseminação se configura como uma espécie de genealogia da experiência das populações africanas e seus descendentes no espaço da diáspora. A proposta insere e articula as diferentes motivações, contextos e consequências das diásporas africanas internas e externas ao espaço do continente africano na longa duração e em sua diversidade.

A nota de apresentação da Reunião do Comitê Científico, realizada na Universidade Federal de São Carlos em 2014 para a elaboração do IX volume da HGA, aponta que uma das lacunas a serem preenchidas no que tange aos oito volumes anteriormente publicados é a falta de difusão dos materiais para fins educacionais (UNESCO/HGA, 2014). Os livros didáticos ainda não incorporaram de maneira orgânica os conteúdos da HGA, havendo a necessidade de que a "renovação da educação em história é de natureza urgente" (HGA, 2014 p. 2). Neste documento há a indicação da criação da 
Utilização Pedagógica da História Geral da África (UPHGA), com um conjunto de ações para fomentar a difusão e o compartilhamento dos conteúdos da HGA. Dentre as ações propostas estão a elaboração de livros, guias, materiais audiovisuais e multimídia para a elaboração dos "conteúdos pedagógicos sobre o uso da Diáspora Africana” (HGA, 2014, p. 3). As sínteses da HGA publicadas em dois volumes em português tiveram por objetivo oferecer ao público leitor essa possibilidade de trabalho com as informações dos oito volumes.

Ao que parece, o debate contemporâneo deverá considerar o que se propõe em torno desse conceito de Africanidade global, que no plano temporal suplanta as narrativas e cronologias que vão desde os "missionários", passando pelos “viajantes" e "exploradores" do século XV ao discurso etnológico (MUDIMBE, 2013). Em outra parte, organizam-se as referências a pensadoras e pensadores cujas obras situam-se nos estudos pós-coloniais, estudos culturais e estudos subalternos.

Tais linhas teóricas buscam uma vanguarda ao colocarem no centro da discussão epistemológica os objetos teóricos protagonizando os subalternizados e colonizados, avaliando as "bibliotecas coloniais", conceito inicialmente desenvolvido por Mudimbe (2013) para caracterizar os modos de construção das ciências humanas e sociais como universais, mas que tem uma base epistemológica no Ocidente (MBEMBE, 2014; BIAYA, 1995, p. 116) como apanágio teórico e metodológico dos centros epistêmicos. A "biblioteca colonial" é uma metáfora de representação sobre a África e seus descendentes que agrega um variado repertório de obras, músicas, imagens que sustentam, em certa medida, um questionamento sobre "qual o significado do termo África nos discursos modernos, do conhecimento e do saber" (DIALLO, 2013, p. 7).

Há nesse sentido uma proposição que deriva dessas perspectivas contemporâneas de pluralizar as fontes inserindo-as no campo de uma justiça cognitiva que visa propor outras bases epistemológicas a partir dos quais se compõem os conhecimentos. Dito de outro modo, há uma compreensão de que as fontes e as narrativas que foram disponibilizadas na narrativa da longa duração das experiências da diáspora levaram não apenas a equívocos, mas a práticas centradas em narrativas estereotipadas justificadas pela "biblioteca colonial”.

Para Paulin J. Hountondji, a mundialização, como conceito que marca o caráter global de circulação, afeta não somente a economia ou os territórios, mas os saberes (HOUNTONDJI, 2008). Posicionar-se a partir de uma esfera diaspórica 
significa reposicionar a geografia dos territórios de modo desterritorializado, na medida em que são cada vez mais povoados por falantes de múltiplas línguas. Requer pluralizar a narrativa histórica na qual a periodização e a narrativa única não são mais as únicas referências centrais a serem consideradas. Para Paul Gilroy, a diáspora "é um conceito que problematiza a mecânica cultural e histórica do pertencimento" (GILROY, 2001, p. 151).

Embora essas perspectivas contemporâneas sejam ainda incipientes, atingem algumas das questões centrais da historiografia. Essa proposta se insere em uma nova agenda global de investigação (HOUNTONDJI, 2008) que pressupõe outra base epistemológica, que se aproprie de saberes locais para que se pretenda constituir pontos de conexão em um debate global (ADESINA, 2008). Na perspectiva aqui desenhada, as experiências da diáspora africana, a partir da abertura do conceito de Africanidade global, podem fazer emergir essas conexões. Isso permitirá, como na perspectiva de Zeleza (2005), debruçar-se na historiografia inserindo temas de estudo globais, regionais e locais a partir de como a história tem sido estudada e produzida.

O uso da diáspora a partir da experiência dos deslocamentos das populações africanas com muitas nuances e leituras ainda é objeto de múltiplas interpretações. Há disputas não apenas no uso, com as datações do tráfico e escravização das populações africanas, mas na definição do conceito, especialmente na contemporaneidade com as questões das imigrações. Naquilo que propicia de criativo é possível utilizá-lo na invenção de outros laços de pertencimento com o estabelecimento de uma cultura própria que na experiência da população negra significou formas de lidar com o sofrimento, a morte e a resistência, mas também produziu uma pluralidade estética, cultural e epistêmica. Há, nessa proposta, a hipótese de que o amplo conhecimento dessas experiências auxilie no entendimento de outras conexões e laços de pertencimento.

O contato com uma narrativa historicamente orientada pode contribuir e fomentar uma apropriação dos conteúdos. Esse desafio adquire outros contornos para o contexto global e da educação, bem como das análises sobre as relações raciais na contemporaneidade. 0 ethos neoliberal que nos impõe um modelo de gestão social na "época na qual o tempo (curto) se presta a ser convertido em força reprodutiva da forma-dinheiro" (MBEMBE, 2014, p. 13) nos forçará a uma análise mais aprofundada do que significará nossa ação no tempo presente. James Baldwin escreveu originalmente em 1963 o livro “Da próxima vez, o fogo: o racismo nos EUA”, na obra que trata dos desafios 
colocados às relações raciais nos EUA, o autor escreve ao seu sobrinho uma carta com conselhos e análises do que significava ser negro na sociedade estadunidense da época e diz: "Agir é comprometer-se, e comprometer-se é ficar em perigo" (BALDWIN, 1967, p. 25). Esse parece ser o momento de retomar os rastros das pessoas que pavimentaram o caminho que nos trouxeram aqui e constituir uma ação comprometida com justiça e igualdade, o que deverá ser feito compreendendo o risco que esse tempo emerge. 


\section{The "Global Africanness" project for writing the history of the African diaspora}

Abstract: This text aims to present some notes for a discussion on the interpretation and historical narrative around the writing of the history of contemporary Africa. The proposal is linked to a debate within the proposition of a "Global Africanness" presented by historians and historians dedicated to the study of this field. Still as an emerging concept, what constitutes "Global Africanness" is a kind of genealogy of the experience of African populations and their descendants in THE diaspora space. The proposal inserts and articulates the different motivations, contexts, and consequences of the African diasporas in the long term and in their diversity. Our aim is to contribute to the debate concerning the introduction of theoretical and methodological aspects that mark the contemporary scene in contemporary historiographic discussion about the reading of new contributions to African historiography.

Keywords: History of Africa. African diaspora. Global africanness. 


\section{El proyecto de "Africanidad Global" para una escritura de la historia de la diáspora africana}

Resumen: Este artículo presenta algunas notas para una discusión sobre la interpretación y narrativa histórica en torno a la escritura de la historia de África contemporánea. La propuesta se vincula a un debate en el interior de la proposición de una "Africanidad Global” presentada por historiadores e historiadoras dedicados al estudio de ese campo. Aún como un concepto emergente, lo que se configura como "Africanidad Global” es una especie de genealogía de la experiencia de las poblaciones africanas y sus descendientes en el espacio de la diáspora. La propuesta insiere y articula las diferentes motivaciones, contextos y consecuencias de las diásporas africanas en la larga duración y en su diversidad. Se busca contribuir con este debate junto a la introducción de los aspectos teóricos y metodológicos que balizan el escenario contemporáneo de la discusión historiográfica contemporánea de la lectura de nuevos aportes a la historiografía africana.

Palabras clave: Historia de África. Diáspora africana. Africanidad global. 


\section{REFERÊNCIAS}

ADESINA, Jimi. Archie Mafeje and the pursuit of endogeny: against alterity and extroversion. Africa Development, v. 33, n. 4, p. 133-152, 2008.

BALDWIN, J. Da próxima vez o fogo: o racismo nos EUA. Trad. Cristiano Monteiro Oiticica. Rio de Janeiro: BUB-Biblioteca Universal Popular.1967.

BARBOSA, M. S. A perspectiva africana na História Geral da África (Unesco). Tempo, Niterói, v. 24, n. 3, p. 400-421, dez. 2018.

BHABHA, H. K. O local da cultura. Tradução Myriam Ávila, Eliana L. Reis e Gláucia R. Gonçalves. Belo Horizonte: Editora da UFMG, 1998.

BIAYA, T. K. Dérive épistémologique et écriture de l'histoire de l'Afrique contemporaine. Politique Africaine, Paris, n. 60, p. 110-116, 1995.

BLANCO, A. Incubadoras de redes diáspora de los saberes. In: MEYER, J-B. (coord.). Diáspora hacia la nueva frontera. Observatorio Mical, 2015. p. 187216.

BRAH, A. Cartografías de la diáspora: identidades en cuestión. Tradução Sergio Ojeda. Madri: Traficantes de Sueños, 2011.

BRASIL. Diretrizes Curriculares Nacionais para a Educação das Relações Étnico-Raciais e para o Ensino de História e Cultura Afro-Brasileira e Africana. Brasília: Conselho Nacional de Educação, MEC, 2004.

BUCK-MORSS, S. Hegel e o Haiti. Tradução Sebastião Nascimento. São Paulo: n-1 Edições, 2017.

CRUZ, A. C. J. Antirracismo e educação: uma análise das diretrizes normativas da Unesco. 2014. Tese (Doutorado em Educação) - Universidade Federal de São Carlos, São Carlos, 2014.

DIALLO, I. Une veritable bibliotheque africaine: 59 questions pour mieux comprendre les réalités du continente. CODESRIA : Senegal, 2013. http:// pointsud.org/wp-content/uploads/AFRICA-NKO-CODESRIA-POINT-SUD-28-31Jan-2013-Press-Review-Revue-de-presse.pdf

FALAIZE, B. 0 ensino de temas controversos na escola francesa: os novos fundamentos da história escolar na França? Tempo e argumento, v. 6, n. 11, 2014. 
FALAIZE, B. L'enseignement de l'esclavage et de la traite négrière dans l'espace scolaire hexagonal. INRP, 2009.

FISTETTI, F. Théories du multiculturalisme: uns parcours entre philosophie et sciences sociales. Paris: Éditions la découverte, 2009.

FURTADO, C. A. O continente africano e a produção africana do conhecimento. Relea. Revista Latino-Americana de Estudos Avançados, v. 1, n. 1, p. 118-137, jan./jun. 2016.

GIDE, A. Avant-propôs. Presence Africaine, n. 1, 1947.

GILROY, P. O Atlântico negro: modernidade e dupla consciência. Rio de Janeiro: Editora 34, 2001.

HABERMAS, Jürgen. Verdade e justificação: ensaios filosóficos. Tradução Milton Camargo Mota. São Paulo: Loyola, 2004.

HALL, S. Da diáspora identidades e mediações culturais. 1. ed. atual. Belo Horizonte: Editora UFMG, 2009.

HALL.S. A relevância de Gramisci para os estudos de raça e etnicidade. In: Da diáspora identidades e mediações culturais. 1. ed. atual. Belo Horizonte: Editora UFMG, 2009.

HALL, S. Identidade cultural e diáspora. Revista do Patrimônio Histórico e Artístico Nacional, n. 24, p. 68-75, 1996.

HALL, S. A centralidade da cultura: notas sobre as revoluções culturais de nosso tempo. Educação e Realidade, Porto Alegre, n. 2, v. 22, p .5, 1997.

HAMP TÉ B , A. La mémoire parole vivante de l'Afrique. Le Courrier de l'Unesco. La Afrique et son histoire, ano XXXII, n. 8/9, p. 5-7, 1979.

HOUNTONDJI, P. Duas perspectivas de estudos africanos. Revista Crítica de Ciências Sociais, n. 80, p. 149-160, mar. 2008.

KI-ZERBO J. Para quando a África? Entrevista com René Holenstein. Rio de Janeiro: Pallas, 2006.

KI-ZERBO, J. Introdução geral. In: UNESCO. Metodologia e pré-história da África. 2010. v. 1.

KI-ZERBO, J. Un continent en quete de son passé. Le Courrier de l'Unesco. La Afrique et son histoire, ano XXXII, n. 8/9, p. 7-8, 1979. 
KOUASSI, E. K. A África e a Organização das Nações Unidas. In: UNESCO. História geral da África. 2010. v. VIII, p. 1053-1094.

LE COURRIER de l'Unesco. La Afrique et son histoire. Ano XXXII, n. 8/9, p. 4-70, 1979.

MAZRUI, A. África desde 1935. In: UNESCO. História geral da África. 2010. v. VIII.

MBEMBE, A. Afropolitanismo. Tradução Cleber Daniel Lambert da Silva. Áskesis. Revista dos Discentes do Programa de Pós-Graduação em Sociologia da UFSCar, v. 4, n. 2, p. 68-71, jul./dez. 2015.

MBEMBE, A. Crítica da razão negra. Portugal: Antógona, 2014.

MBEMBE, Achille. Necropolítica. Arte \& Ensaios, [S.I.], n. 32, mar. 2016.

MBEMBE, A. Afriques indociles: christianisme, pouvoir et etat en société postcoloniale. Paris: Editions Karthala, 1988.

M'BOW, A.-M. L'histoire generale de l'Afrique. Le Courrier de l'Unesco. La Afrique et son histoire. Ano XXXII, n. 8/9, p. 5-7, 1979.

McCLINTOCK, A. Le postcolonialisme et l'ange du progrès. Ruptures postcoloniales: Les nouveaux visages de la société française. Paris: La Découverte/Cahiers libres, 2010. p. 96-104.

MEZZADRA, S. (org.). Estudios postcoloniales: ensayos fundamentales. Tradução Marta Malo. Madri: Traficantes de Sueños, 2008. p. 167-196.

MKANDAWIRE, T. (ed.) African intellectuals. Londres/Nova York: Codesria/Zed Books, 2005.

MUDIMBE, V. Y. A invenção da África: gnose, filosofia e a ordem do conhecimento. Portugal-Angola: Edições Pedago e Edições Mulemba, 2013.

NDIAYE, P. Pour une histoire des populations noirs en France: preálables theoriques. Le Mouvement Social, n. 215, p. 91-208, 2005.

ONU. Livreto sobre a Década Internacional de Afrodescendentes da ONU. Departamento de Informação Pública da ONU (DPI) e pelo Escritório do Alto Comissariado da ONU para os Direitos Humanos (ACNUDH). Trad. Lins Franciotti. 2015, 32p.

POUCHEPADASS, J. Les Subaltern Studies ou la critique postcoloniale de la 
modernité. L’Homme, n. 156, p. 161-186, out./dez. 2000.

SAID, Edward. Orientalismo: o Oriente como invenção do Ocidente. São Paulo: Companhia das Letras, 2007.

TROUILLOT, M-P. Silenciando o passado: poder e a produção da história. Curitiba: Huya, 2016.

UNESCO. Atelier Epistémologique pour l'élaboration du Volume IX de l'Histoire genérale de l'Afrique: Nouvelle conceptualisations de l'Afrique et de ses Diasporas dans les sciences sociales et humaines. Note de Présentation. 8 p.

ZELEZA, P. T. Banishing the silences: towards the globalization of African history. Dakar: Codesria, 2005.

SOBRE A AUTORA:

Ana Cristina Juvenal da Cruz é doutora em educação pela Universidade Federal de São Carlos. Atua como professora-adjunta no Departamento de Teorias e Práticas Pedagógicas e vice-diretora do Centro de Educação e Ciências Humanas, CECH-UFSCar.

E-mail: anacjcruz@gmail.com

Recebido em: dezembro de 2018

Aprovado em: abril de 2019 